\title{
PRECONCEITO E SEPARATISMO NO DISCURSO: UM DISCURSO SEPARATISTA GAÚCHO*
}

\author{
Diana Luz Pessoa de Barros
}

\begin{abstract}
RESUMO: Ce texte examine la construction du récit et du discours séparatiste, à partir de la théorie sémiotique. On analyse surtout le chapitre 10 "O país dos gaúchos - Manifesto do povo gaúcho", du livre d'Irton Marx, Vai nascer um novo país: República do Pampa Gaúcho. D'après l'analyse du texte, on peut conclure que le discours séparatiste se présente comme un discours raciste, à double sens. Le discours séparatiste s'appuie sur le discours du racisme communautaire contemporain (de la différence) et aussi sur le racisme universaliste ou discriminatoire (de l'inégalité ou de la supériorité), qui a présidé à la formation des empires coloniaux ou des systèmes d'esclavage.
\end{abstract}

PALAVRAS-CHAVE: discurso separatista, narrativa separatista, teoria semiótica, racismo e separatismo.

Neste trabalho examinamos como os textos constroem a narrativa e o discurso separatista.

Apoiamo-nos, sobretudo, na teoria semiótica da narrativa e do discurso e tomamos por base para a análise principalmente o cap. 10 "O País dos Gaúchos Manifesto do povo gaúcho", do livro de Irton Marx, Vai nascer um novo país: República do Pampa Gaúcho.

Para o exame da narrativa separatista partimos dos seguintes aspectos da teoria semiótica:

a) a teoria semiótica concebe dois tipos de relações entre sujeitos, as contratuais e as polêmicas. As relações contratuais são relações entre um Destinador e um Destinatário, ou seja, relações de manipulação entre sujeitos. O Destinador propõe um acordo, segundo certos valores, e trata de persuadir o Destinatário a aceitá-lo; o Destinatário, por sua vez, interpreta a proposta do

\footnotetext{
* Este texto foi apresentado na Reunião da Associação Brasileira de Lingüística, na 45 ${ }^{\text {a }}$ Reunião da SBPC, em julho de 1993, e publicado posteriormente no Boletim da ABRALIN.
}

Diana Luz Pessoa de Barros é professora na Universidade de São Paulo 
Destinador, nela (ou nele) acredita ou não e aceita ou recusa o contrato. As relações polêmicas são relações entre sujeito e anti-sujeito, isto é, entre sujeitos interessados em um mesmo objeto-valor e que por ele entram em conflito. São relações de luta, marcadas pela derrota ou pela vitória das ações dos sujeitos;

b) o segundo aspecto diz respeito ao fato de que as relações intersubjetivas (as que vigem entre Destinador e Destinatário, principalmente) são regulamentadas por simulacros que se estabelecem entre os sujeitos e que fundamentam as relações passionais. Os simulacros são figuras que representam as competências respectivas que o Destinador e o Destinatário se atribuem reciprocamente. Dessa forma, os simulacros intervêm como algo prévio, necessário a qualquer programa de manipulação intersubjetiva. Objetos imagináveis que o sujeito projeta, segundo sua formação ideológica, os simulacros, embora não tenham nenhum fundamento intersubjetivo, determinam de maneira eficaz as relações entre sujeitos.

As narrativas separatistas foram examinadas a partir dessas concepções. Em outras palavras, o separatismo no texto analisado é entendido tanto como a ruptura de contratos entre Destinador e Destinatário, segundo os simulacros construídos entre eles, quanto como conflito entre sujeitos que aspiram aos mesmos valores.

Comecemos com a questão da ruptura de contrato. O Destinador identifica-se como o Brasil, o governo e os políticos do Brasil, o poder central brasileiro, o centro do Brasil, o povo brasileiro. O Destinatário, como o povo gaúcho, a República do Pampa Gaúcho, o sul. O acordo seria um acordo de manter o equilíbrio entre as partes que compõem o todo Brasil. Retomaremos à frente a questão da parte vs. todo.

A ruptura do contrato é decorrência da interpretação dada pelo Destinatário ao acordo e ao seu cumprimento pelo Destinador. O Destinatário julga que:

a) o Destinador não cumpriu a sua parte no acordo;

b) o Destinador não tem qualificações para cumprir o contrato;

c) o Destinador não tem qualificações para ser Destinador.

Em resumo, o Destinador Brasil não cumpriu sua parte no contrato, por não ter qualificações para fazê-lo, por lhe faltar competência. Por outro lado, o Destinatário tem as qualidades que faltam ao Destinador. A oposição é, portanto, entre incompetência vs. competência; ineficiência vs. eficiência. Veja-se o trecho que segue: "O Brasil deve reconhecer que falhou em seus propósitos desde o início, que não comporta, dado seu enorme território, governar seus súditos" (p.56).

Entendida a competência como um arranjo de qualidades modais necessárias para que o sujeito faça, no caso cumpra o acordo, ou seja, como o querer-fazer, o saber-fazer e o poder-fazer, pode-se dizer que, nos diferentes momentos do texto examinado, o Brasil e os brasileiros são qualificados (ou desqualificados) como sujeito que não quer, não sabe e não pode fazer.

O brasileiro não quer fazer, pois é preguiçoso, não tem vontade de trabalhar, nem tradição de trabalho. O gaúcho, ao contrário, quer fazer e tem 
tradição de trabalho, de luta, de esforço e de dedicação:

Sabemos que durante dezenas de anos nós alimentamos grande parte do Brasil, mas o governo, ao invés de reconhecer este fato, prefere fazer obras e investimentos em regiões cujos povos não possuem um mínimo de tradição em trabalhar e de pensar um pouco mais. São em sua enorme maioria simples predadores, destruidores da natureza, e por si só nada fazem ou pouco produzem. Com raras exceções, paira o espectro da preguiça, da falta de vontade, em grande parte do Brasil (p.54).

Nunca fomos e jamais seremos parasitas, pois produzimos quase tudo de fato e de direito e chegou o momento histórico de pararmos de alimentar ou enriquecer pessoas que nada ou quase nada fazem por si mesmas. Estamos sendo prejudicados há séculos pelos brasileiros em geral (p.54). Nossa realidade é bem outra. Temos uma tradição, uma filosofia de trabalho, de boa vontade e o nosso crescimento se deu pelo esforço, amor, luta e dedicação do nosso próprio povo (p.54).

Embora não haja menção explícita, essa parte da desqualificação é endereçada principalmente ao Nordeste. Retoma-se o velho lugar comum da ideologia dominante, o da preguiça do brasileiro e, sobretudo, do nordestino.

O brasileiro não sabe-fazer ou sabe menos que o gaúcho e não tem capacidade para aprender: é ignorante, burro e não pensa. Já o gaúcho alia o conhecimento ao brilhantismo:

Nós, gaúchos, passamos vergonha ao encararmos os estrangeiros nas nossas ruas, que nos olham com desprezo, como sendo velhacos, incompetentes e ignorantes, sem o poder de ação, quando na verdade eles não sabem que o povo gaúcho nada tem a ver com os erros técnicos e a discrepâncias do governo do Brasil. Os estrangeiros não sabem que somos um povo diferente, que só não somos ainda independentes porque deixamos passar dezenas de anos na esperança que tudo pudesse se modificar de uma hora para outra (p.54).

O brasileiro tampouco pode-fazer, como no trecho acima citado em que lhe falta o poder de ação. O não poder-fazer é decorrência, sem dúvida, do tamanho do país e de outras razões físicas, mas o traço que mais fortemente aparece é o dos valores morais, éticos. Opõem-se os brasileiros aos gaúchos por:

$\begin{array}{lll}\begin{array}{l}\text { corrupção } \\ \text { falta de idoneidade }\end{array} & \text { vs. } & \text { honestidade } \\ \begin{array}{l}\text { sem-vergonhice } \\ \text { descaramento }\end{array} & \text { vs. } & \text { brio } \\ \text { medo } & \text { vs. } & \text { bravura, coragem } \\ \text { ganância } & \text { vs. } & \text { desprendimento. }\end{array}$

A moralização marca a Nova República e define o discurso conservador. No texto em exame, a falta de valores morais equivale à ausência não apenas de competência para a ação, mas principalmente de qualificações para ser, para existir. Vejam-se os trechos que seguem:

Toda vez que o povo gaúcho se insubordinava com as atitudes dos governantes do Brasil, era porque via desrespeito para com a sua e a nossa gente e mais uma vez o dedo gaúcho apertava o gatilho da moralidade, tentando por outros caminhos, fazer mais justiça ao povo 
desta terra (p.53).

Nossas famílias deverão conduzir-se dentro de uma harmonia invejável. Sem brigas ou discussões, sem queixas e incompreensões descabidas. Nossos chefes de família deverão abandonar certas condutas ou certas práticas que só têm prejudicado e até destruído nossa gente. Nosso povo deve abandonar a prática da mentira, do beber em demasia, do lograr, do rir, ou fazer os outros de bobo. Deve abandonar os hábitos nocivos tais como fofoquear, desprezar ou caçoar de alguém, maliciar a conduta ou o jeito das pessoas. Não deve andar sem bons modos, cuspir nas calçadas, andar mal barbeado, com mau cheiro, mal vestido e sempre apto a fazer algo que de uma forma ou outra acabe por prejudicar o seu semelhante. A população do PAMPA deve abandonar a mania de fazer intrigas, ser maldosa para com as pessoas ou para com os animais [...]. Nossos jovens devem se desenvolver sadios, fortes e com uma grande vontade de contribuir na formação intelectual do povo do PAMPA. Todos devem adotar bons modos e abandonar aqueles que só os prendem às práticas impuras e que os conduzem a uma perdição total. Devem deixar de só pensar em sexo, em malícias, sacanagens, drogas, mentiras e fofocas (p.142-143).

Dessa forma, os sujeitos que não estão aptos para cumprir o contrato assumido, pois não têm competência para a ação, nem qualificações para ser, não podem assumir o papel de Destinador. Em outros termos, se a relação entre Destinador e Destinatário é desequilibrada, cabendo ao Destinador a decisão, o estabelecimento das regras, a doação de modalidades ao Destinatário, essa posição não pode ser ocupada por um ser inferior, em detrimento do superior.

A oposição inferioridade (do brasileiro) vs. superioridade (do gaúcho) manifesta-se claramente:

Os ideais farroupilhas voltam à tona, e o espírito de valentia, da liberdade, do inconformismo, por estar sendo governado por seres inferiores a nossa cultura (p.7).

Um dos elementos mais fortemente apontados para comprovar que seres inferiores não podem ocupar posição acima da dos superiores, é o fato de que o Destinador-Brasil não cumpre a contento seu papel de julgador e de sancionador, isto é, não julga e não sanciona, corretamente, o Destinatário-gaúcho, não reconhece suas qualidades e não lhe dá a recompensa, a retribuição que lhe é devida.

Assim, o Brasil tem em relação ao gaúcho, má-vontade, indiferença, nãoreconhecimento, desrespeito, desprezo, desconsideração. Em outras palavras, o Destinador ou não quer fazer nada pelo Destinatário ou quer fazer-lhe mal, prejudicá-lo, sem reconhecer nele o herói digno de retribuição, de recompensa, pois os gaúchos aumentaram o território brasileiro, lutaram com uruguaios, argentinos e paraguaios e alimentaram o Brasil, como aponta o texto citado a seguir:

Ao longo dos séculos, a região gaúcha foi palco de sangrentos conflitos armados na ânsia de proteger o solo gaúcho e brasileiro, sem que o próprio Brasil reconhecesse a importância e a bravura do povo desta terra. O próprio território brasileiro foi aumentado pelos gaúchos, que 
disputaram palmo a palmo cada centímetro de terra contra o exército colonialista espanhol nos tempos do império. Foram sempre os gaúchos que se confrontaram com uruguaios, argentinos e paraguaios (p.52).

Quase nada recebemos em praticamente 400 anos de história gaúcha, a não ser humilhações, desprezo e desconsiderações provindas dos olhares maliciosos e das intrigas de bastidores dos palácios dos governos regionais (p.54).

Essas mesmas razões já levaram os gaúchos, dizem os textos, a optar em outra ocasião por uma solução separatista de ruptura do contrato.

Dessa forma, se não há a contrapartida do Destinador, o contrato é ruim para o Destinatário, ou seja, os gaúchos dão muito e recebem pouco ou nada. Os gaúchos trabalham e os outros são parasitas: aproveitam-se do trabalho dos gaúchos que "nunca foram e jamais serão parasitas".

Esse é, sem dúvida, um dos simulacros que esteve por detrás do movimento separatista em São Paulo, em 32, e que hoje tem sido retomado. Um articulista, em texto jornalístico com o subtítulo de separaSão, ou seja, separa São Paulo, fez recentemente, uma estimativa do tanto que São Paulo paga de impostos e do pouco que recebe de volta em benefícios e de como, com esse dinheiro, poderíamos, por exemplo, pagar melhor os professores da rede de ensino estadual e melhorar significativamente a situação da educação no Estado.

Em suma, aquele que quer se separar considera o acordo unilateral, benéfico para uma das partes apenas. Em outras palavras, os bons não estão sendo recompensados e os maus punidos.

As relações entre brasileiros e gaúchos foram examinadas como relações contratuais entre Destinador e Destinatário e podem ser agora repensadas como relações de conflito, de polêmica entre sujeitos interessados nos mesmos valores (poder, riqueza) e que por eles brigam. As relações entre sujeitos são, ao contrário das relações entre Destinador e Destinatário, relações equilibradas, o que nos permite entender melhor o termo separação. A proposta do autor é de separação e não de divisão do país. O Brasil está sendo concebido como um todo-conjunto de partes diferentes (omnis, no latim) que podem e devem ser separadas e não com um todo-inteiro ou unitário (totus) que se pode, por exemplo, dividir, fracionar. O traço semântico que preside, por conseguinte, a separação é o da diferença entre sujeitos, como mostra o extrato a seguir:

O Brasil deve reconhecer que falhou em seus propósitos desde o início, que não comporta, dado o seu enorme território, governar seus súditos, cujas idéias e tradições diferem a cada quilômetro rodado (p.56).

O discurso separatista coloca-se como discurso da diferença, ou seja, um discurso racista. É preciso lembrar, porém, que Pierre André Taguieff, retomado por Marilena Chauí na sua aula inaugural sobre racismo e cultura, em março de 1993, na FFLCH-USP, distingue dois tipos de racismo:

- o racismo universalista ou discriminatório que hierarquiza as espécies ou as raças, indo da inferior à superior e que afirma a naturalidade da hierarquia, da desigualdade. Foi o racismo dos impérios coloniais, da escravatura, do nazismo, do 
fascismo e é presidido pela idéia (ou simulacro) de nação;

- o racismo comunitarista ou diferencialista é o racismo contemporâneo: se cada comunidade-nação tem sua tradição, sua história, seus costumes, sua origem, sua língua, sua religião, é preciso garantir a diferença, não contaminar a diferença. No dizer dos dois autores citados, esse discurso retoma e aproveita o tema central do anti-racismo dos anos 60, qual seja, o do direito à diferença. O discurso racista da diferença é hoje dominante, pois estamos na época da formação das comunidades (européia, por exemplo) e do desaparecimento (ou da tentativa de) da idéia de nação.

O discurso separatista do sul é, sem dúvida, como apresentamos, um discurso racista da diferença entre as partes que se pretende separar. Os gaúchos têm tradições seculares, hábitos diferentes dos dos brasileiros e com eles não querem ser confundidos, têm vergonha disso e têm direito às diferenças. No trecho abaixo o gaúcho não quer, por exemplo, tornar-se sertanejo:

Somos um povo orgulhoso de suas tradições, sonhador, e em nossas pretensões futurísticas queremos construir uma nação de respeito pela conduta da sua gente [...] Por isto, se torna necessária a nossa separação do Brasil, pois sob sua guarda jamais conseguiremos colocar um plano de recuperação econômica em prática, continuaremos eternamente em decadência, deixando de ser gaúchos para nos tornar sertanejos, perdendo cada vez mais a nossa identidade.

Esse tipo de discurso racista não basta porém para os propósitos do autor, pois é um discurso racista, mas não separatista, já que vige nas novas comunidades que se formam enquanto todo. Quando o texto trata da integração dos negros, por exemplo, é esse o discurso utilizado:

Acerca dos problemas raciais - $\mathrm{O}$ sistema entende que a raça negra deve ser definitivamente incorporada à comunidade em geral.

a) $\mathrm{O}$ negro deve acreditar em suas potencialidades pessoais;

b) $\mathrm{O}$ negro deve partir para a busca de novos conhecimentos $\mathrm{e}$ abandonar costumes e hábitos puramente medievais; [...]

k) O negro deve orgulhar-se da sua raça e buscar na sua própria gente o seu companheiro ou a sua companheira de vida;

m) O negro no PAMPA também terá o seu direito garantido e participará dos destinos da nossa gente. O mesmo acontecerá com os índios e outros (p.145).

O discurso separatista necessita, portanto, também do discurso racista nacionalista (o do fascismo, do nazismo, dos impérios coloniais), para ser ao mesmo tempo racista e separatista. Deve ser um discurso de formação de uma nova nação, cuja comunidade não é assegurada nem pela língua, nem pela religião, mas pela consciência de comunidade e pela etnia. É a idéia já apontada de que os gaúchos são superiores e têm consciência de que pertencem a uma comunidade outra, que não é a brasileira.

Nessa conjunção entre os dois tipos de discurso racista, o da diferença e o nacionalista, constrói-se o discurso separatista e com ele forma-se uma nova nação "forte e cheia de virtudes", como prega o texto examinado. 